\title{
Glicoimunologia: uma janela de desafios e oportunidades para uma Imunologia mais doce
}

\author{
Zélia Silva ${ }^{1}$ e Paula A. Videira ${ }^{1,2}$ \\ ${ }^{1}$ UCIBIO, Departamento Ciências da Vida, Faculdade de Ciências e Tecnologia, Universidade NOVA de Lisboa, Portugal \\ ${ }^{2}$ CDG \& Allies-PPAIN, Professionals and Patient Associations International Network
}

\begin{abstract}
Glycoimmunology: a window of challenges and opportunities to a sweeter Immunology - All of our cells are coated by a complex set of sugars, called glycans or carbohydrates, which confers each cell, its own identity and modulate its function. Glycans decorate all secreted and membrane proteins and, due to their privileged position, mediate the interaction between cells and molecules. The immune response, characterized by cell-cell interactions and molecular recognition, is the ideal model system for understanding glycan's role in biology. The term "glycoimmunology" was created to define the study of glycans in the immune system. In this article we give some examples of the role of glycans and glycan-recognizing molecules in the different functions of cells and organs of the immune system in humans. Glycans influence the mechanisms that lead to autoimmunity, immunodeficiency, infection, and other diseases related to the immune response, such as cancer. So, glycoimmunology has extended our knowledge in very broad fields such as immunological diseases and will shape the design of new therapeutic approaches.
\end{abstract}

$\mathrm{Q}$ ualquer uma das nossas células é revestida por um complexo conjunto de hidratos de carbono, que lhe conferem uma identidade própria e modulam a sua função. Os hidratos de carbono decoram todas as proteínas membranares e secretadas, tendo uma posição privilegiada para mediar a interação entre células e moléculas. A resposta imunitária, tipificada por interações célula-célula e reconhecimento molecular, é o modelo ideal para compreender os eventos mediados por hidratos de carbono bem como a sua biologia. Assim surge o termo "Glicoimunologia" que estuda o papel dos hidratos de carbono no sistema imunitário, bem como na fisiopatologia das doenças relacionadas e na terapia. Neste artigo destacamos alguns exemplos do papel dos hidratos de carbono e das moléculas que os reconhecem nas diferentes funções de células e órgãos do sistema imunitário humano. Os hidratos de carbono influenciam os mecanismos que desencadeiam autoimunidade, imunodeficiência, infeção e outras doenças relacionadas com a resposta imunitária, como o cancro. Assim, a "Glicoimunologia" alargou o nosso conhecimento em áreas muito abrangentes como as doenças do foro imunológico e permitiu o desenvolvimento de novas abordagens terapêuticas.

\section{Os hidratos de carbono e a biologia da célula}

Todas as células, incluindo as humanas, são revestidas por uma densa camada de hidratos de carbono, designada por glicocálix, que está ancorada à célula através de glicoproteínas e glicolípidos membranares e que, para além do seu papel estrutural, desempenha um conjunto de funções muito importantes, tais como:

i) Sinalização celular: padrões de glicosilação específicos podem afetar as vias de sinalização no caso de serem eles próprios ligandos ou interferirem com a ligação entre recetor-ligando. Podem ainda afetar a agregação de recetores.

ii) Proteção celular: funciona como barreira à penetração imprópria de substâncias na célula.

iii) Adesão e migração celular: o glicocálix é uma camada viscosa altamente hidratada facilitadora do movimento celular. Possui proteínas para facilitar a adesão e o movimento celular

A glicosilação é um processo que consiste na adição de monómeros de hidratos de carbono a outros hidratos de carbono, ou no caso de glicoconjugados a proteínas, lípidos ou outros compostos orgânicos. Este processo é catalisado por glicosiltransferases localizadas maioritariamente no retículo endoplasmático e no complexo de Golgi. A frequência e diversidade da glicosilação é dependente da expressão das glicosiltransferases, bem como da disponibi- lidade de substratos dadores e aceitadores. Portanto, cada tipo de célula tem um padrão de glicosilação complexo, mas específico, que inclui também o conjunto das proteínas ou lípidos membranares que estão glicosilados.

Em células humanas, as classes mais comuns de glicoconjugados são:

i) As proteínas $\mathrm{N}$-glicosiladas em que as cadeias de hidratos de carbono estão ligadas a uma asparagina (Asn), localizada na sequência consenso Asn-X-serina (Ser)/treonina (Thr), normalmente através de uma $N$-acetilglucosamina (GlcNAc). As proteínas O-glicosiladas em que os hidratos de carbono estão ligados a um resíduo de serina ou treonina da cadeia polipeptídica, frequentemente através de uma $\mathrm{N}$-acetilgalactosamina (GalNAc). Um exemplo destas são as mucinas, glicoproteínas de elevado peso molecular, que contêm um grande número de locais com O-glicosilação.

ii) Os proteoglicanos têm uma ou mais cadeias de glicosaminas ligadas por um resíduo de xilose a um grupo hidroxilo do resíduo de serina.

iii) As glicoproteínas ancoradas por glicofosfatidilinositol (do inglês, GPI-anchored) têm uma ligação glicosídica entre o fosfatidilinositol e a fosfatidiletanolamina que se liga ao terminal carboxilo da proteína através de uma ligação amida. 
iv) Glicosfingolípidos são os glicolípidos mais abundantes e consistem num polissacarídeo ligado, via glucose ou galactose, ao grupo hidroxilo terminal de uma ceramida. Um gangliosídeo é um glicolípido contendo um ou mais resíduos de ácido siálico.

A diversidade de estruturas glicosiladas presente em cada célula é a base de interações e coordenação/comunicação entre células do mesmo tipo ou de tipos diferentes e também com o microambiente que as rodeia.

A informação biológica codificada em cadeias de hidratos de carbono é provavelmente tão significativa como a que existe nas sequências de aminoácidos de uma proteína. Além das funções estruturais e energéticas que lhes são classicamente atribuídas, sabe-se que participam em diversas atividades biológicas, atuando como portadores de informações, rótulos de tráfego intracelular de algumas proteínas; mediadores específicos nas interações célula-célula e célula-matriz extracelular, na coagulação sanguínea, na cicatrização de lesões, e na resposta imunológica [1]. Vamos falar em maior detalhe do sistema imunitário.

\section{Os componentes do sistema imunitário: como funciona a resposta imunitária}

O sistema imunitário consiste numa rede de células, tecidos, órgãos e, também, moléculas que cooperam para proteger o nosso organismo. Em situações normais, o sistema imunitário é o responsável por defender o nosso organismo contra microrganismos invasores e células danificadas, mantendo o organismo saudável. Existem dois tipos de resposta imunitária:

- A inata ou natural é a primeira linha de defesa rápida não específica. É composta por um conjunto diverso e alargado de células, como monócitos, macrófagos, linfócitos NK (do inglês, natural killer), neutrófilos e células dendríticas (DCs), entre outras, e moléculas que destroem rapidamente os patogénios por lise celular, fagocitose, e outros mecanismos.

- A adaptativa ou adquirida é uma resposta mais tardia, mediada por linfócitos B e T, cujos recetores são altamente específicos para o antigénio. Este tipo de resposta gera memória imunitária, que se traduz numa proteção duradora.

Estes dois ramos de defesa oferecem proteção contra doenças, conferindo imunidade. Na figura 1 podemos ver todas as propriedades do sistema imunitário descritas de uma maneira simplificada.

Os linfócitos B podem diferenciar-se em células plasmáticas, que secretam anticorpos (ou imunoglobulinas Ig) que se ligam especificamente ao antigénio. Existem diferentes tipos de anticorpos (IgG, IgM, IgA, IgE e IgD) com diversas funções imunológicas (neutralização, opsonização, ativação do complemento, ativação de células e indução da morte celular), consoante a sua região efetora (Fc) e subsequente reconhecimento por células ou moléculas efetoras (figura 2).

Os linfócitos T reconhecem epítopos peptídicos apresentados no contexto das principais moléculas do complexo de histocompatibilidade (MHC, do inglês, major histocompatibility complex). As células $\mathrm{T}$ citotóxicas

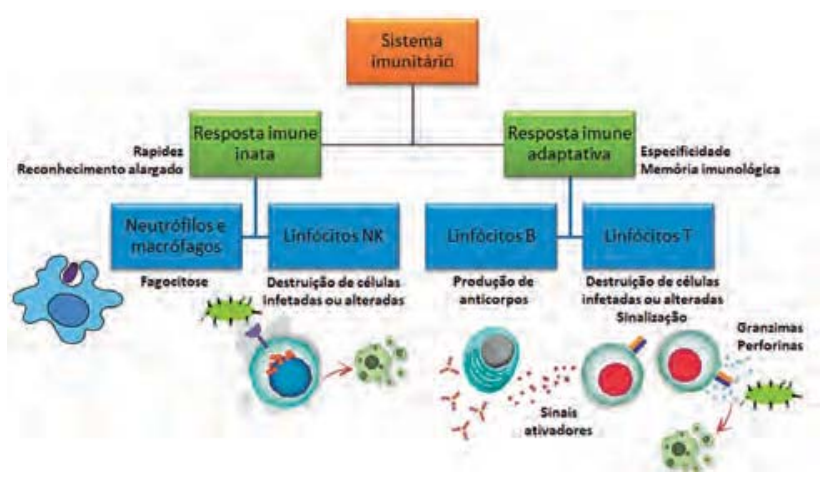

Figura 1 - Após a invasão do nosso organismo por um patogénio, que consegue transpor as nossas barreiras biológicas naturais, este é detetado imediatamente pelas células ou moléculas da resposta imunológica inata, que trabalham em conjunto para responder em função das suas características, quantidade e localização, fagocitando-o e destruindo-o. Neste processo, as células da resposta inata apresentam antigénios derivados dos patogénios aos linfócitos, desencadeando-se assim a resposta adaptativa. Os linfócitos T citotóxicos destroem células infetadas, através da libertação de substâncias como granzimas e perforinas, que as destroem. Os linfócitos $\mathrm{T}$ auxiliares produzem citocinas que induzem a ação de outras células, como os linfócitos B, os linfócitos T e as células da resposta inata. Os linfócitos B produzem anticorpos que por serem reconhecidos por outras células efetoras potenciam a fagocitose e a eliminação das células infetadas.

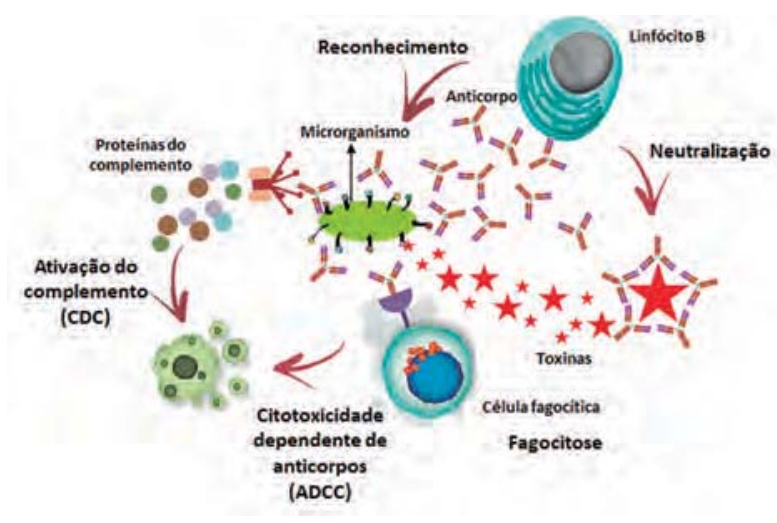

Figura 2 - Principais funções dos anticorpos. Os anticorpos permitem a citotoxidade celular dependente de anticorpos (ADCC, do inglês antibody-dependent cell-mediated cytotoxicity), mediada por linfócitos NK. Permitem também a ativação da cascata do complemento, uma cascata citolítica mediada por um conjunto de proteínas abundantes no soro. Facilitam a fagocitose através do seu reconhecimento por fagócitos. Permitem ainda a neutralização da ação de moléculas como as toxinas, por exemplo.

$\left(\mathrm{CD}^{+}\right)$têm a capacidade de matar células infetadas com vírus ou bactérias intracelulares e células malignas, reconhecendo os epítopos apresentados através do MHC-I. Os linfócitos T auxiliares (Th, CD4 ${ }^{+}$) secretam citocinas relevantes e reconhecem os epítopos apresentados através do MHC-II. Os linfócitos Th diferenciam-se em subtipos definidos essencialmente pelo conjunto de citocinas produzidas. Os principais subtipos são: Th1 (produtores de IFN-ץ), importantes na indução de respostas imunológicas celulares contra células infetadas ou tumorais; Th2 (produtores de IL-4), que suportam respostas imunológicas mediadas por anticorpos; linfócitos Th17 (produtores de IL-17), envolvidos em respostas antimicrobianas e inflamatórias; e células $\mathrm{T}$ reguladoras (Treg), que regulam as respostas imunológicas e são, portanto, responsáveis pela imunostasia (o braço imunitário da homeostasia). 


\section{Glicoimunologia: como está o sistema imunitário relacionado com a glicosilação?}

Qualquer fenómeno imunológico terá inevitavelmente a interferência de hidratos de carbono, pois qualquer que seja a proteína expressa ou secretada por células deste sistema, ela está glicosilada.

Sabemos que alterações na glicosilação estão por detrás de mecanismos que conduzem a autoimunidade, imunodeficiência, infeção e outras doenças relacionadas com a resposta imunitária, como o cancro. Os hidratos de carbono influenciam o desenvolvimento e ativação celular, o reconhecimento de antigénios, a interação de patogénios com o hospedeiro e a regulação das características e função de moléculas efetoras, como as imunoglobulinas. Os hidratos de carbono desempenham por si só funções, mas também, quando conjugados a uma determinada molécula, modulam a função desta, ou podem mesmo atribuir-lhe novas funções. Para além disso, as lectinas, proteínas que reconhecem hidratos de carbono, são amplamente expressas pelo sistema imunitário. A ligação da lectina a determinado tipo de hidratos de carbono é o modo principal de reconhecimento e descodificação da informação contida nas estruturas glicosiladas e sua tradução numa ação biológica.

Existem várias famílias de lectinas identificadas pelos seus domínios de reconhecimento de hidratos de carbono (CRDs). Estas encontram-se amplamente envolvidas na resposta imunitária: (i) as siglecs, que reconhecem ligandos contendo ácido siálico e regulam interações e sinalização celular em linfócitos e outros tipos de células do sistema imunitário; (ii) as lectinas de tipo C (ligação dependente de cálcio), que reconhecem padrões moleculares em patogénios, participando na fagocitose e resposta às infeções. Reconhecem também moléculas endógenas do próprio organismo, controlando respostas autoimunes [2-4]; (iii) as selectinas, um subgrupo de lectinas de tipo C, que regulam a interação de leucócitos no sangue com células endoteliais, permitindo assim a mobilização de leucócitos para focos de infeção; (iv) as galectinas que tipicamente atuam como proteínas estruturais, ligando e organizando domínios membranares na célula ou entre células distintas, e regulando assim uma variedade de sinais a jusante. Algumas lectinas são solúveis e secretadas, como as colectinas, constituídas por um domínio semelhante ao colagénio no terminal amino do CRDs. As colectinas associam-se em oligómeros de 9-27 subunidades. Têm um papel importante no reconhecimento de padrões moleculares não-próprios, opsonizando patogénios e facilitando a sua fagocitose. Contudo, a maioria das lectinas estão localizadas na membrana celular e possuem domínios citoplasmáticos que participam na sinalização intracelular e endocitose. A expressão de diferentes lectinas em diferentes células do sistema imunitário e a integração dos sinais intracelulares a jusante, desencadeada por todas essas lectinas, afeta profundamente a diferenciação e a função das células. Na figura 3 estão sumariados de forma esquemática os papéis dos hidratos de carbono no funcionamento do sistema imunitário.

O envolvimento da glicosilação em diversas funções do sistema imunitário tem sido demonstrado quer em modelos animais deficientes em glicosiltransferases quer em doentes com deficiências congénitas na glicosilação (CDG, do

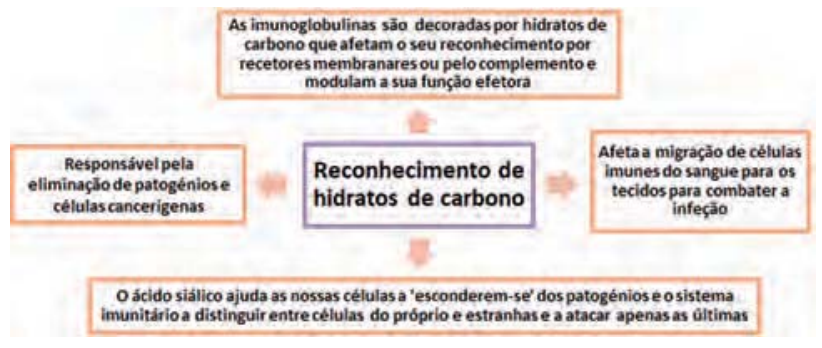

Figura 3 - Principais papéis dos hidratos de carbono no funcionamento do sistema imunitário.

inglês congenital disorders of glycosylation). Por exemplo, a doença da glicosilação CDG IIc ou SLC35C1-CDG, também conhecida como deficiência na adesão de leucócito, tipo II (do inglês leukocyte adhesion deficiency type II, LAD2), caracterizada por ausência de fucosilação em glicoconjugados, incluindo os ligandos de selectinas, que se traduz na adesão deficiente dos leucócitos ao endotélio e que afeta diretamente a resposta às infeções. O conhecimento deste mecanismo veio clarificar o papel das selectinas e dos seus ligandos fucosilados no recrutamento de leucócitos para os tecidos para combater as infeções $[5,6]$. Na sequência da compreensão destes mecanismos moleculares, foram desenhadas algumas moléculas que mimetizam hidratos de carbono, utilizadas como fármacos anti-inflamatórios no intuito de controlar a interação entre os leucócitos e as selectinas presentes no endotélio, logo, no recrutamento de células do sangue para os tecidos [7].

Em relação ao papel dos hidratos de carbono, tome-se como exemplo o monossacarídeo ácido siálico, que é o açúcar terminal mais abundante na superfície celular em humanos. Sabemos que níveis séricos elevados de ácido siálico estão associados a uma série de patologias, como doenças cardiovasculares [8] e cancro [9]. A explicação parece estar no facto de o ácido siálico acompanhar a resposta de fase aguda, desencadeada no fígado em resposta a infeção, inflamação ou lesão tecidular. Por outro lado, um aumento dos níveis de hidratos de carbono sialilados nas imunoglobulinas leva a uma atenuação da resposta imunitária, por alteração do reconhecimento das imunoglobulinas pelos recetores efetores Fc [10]. Além disso, os hidratos de carbono sialilados podem ser reconhecidos por recetores com funções inibitórias, como a siglec 2, promovendo a diminuição de função e apoptose dos linfócitos B [11].

\subsection{Glicoimunologia e autoimunidade}

As doenças autoimunes caracterizam-se frequentemente pela presença de linfócitos B autorreativos ou polirreativos que escapam à seleção negativa durante a sua maturação e produzem anticorpos contra o próprio organismo. Existem duas siglecs (siglec-G e CD22) que têm uma função regulatória na inibição das células autorreativas e na indução de tolerância, por inibição da sinalização associada ao recetor dos linfócitos B. Estas siglecs reconhecem hidratos de carbono decorados com ácido siálico e como estes estão presentes quase exclusivamente em células de vertebrados, e ausentes em microrganismos, sugere-se que o seu reconhecimento esteja geralmente associado a mecanismos de tolerância imune às células do próprio organismo $[12,13]$. 
A deficiência combinada de Siglec-G e CD22 (Siglec 2) que, em modelos animais, conduz à autoimunidade espontânea é outra evidência da relação entre siglecs e autoimunidade. Por outro lado, mutações na enzima $O$-acetilesterase que remove grupos $O$-acetilo do ácido siálico, favorecendo o seu reconhecimento por siglecs, estão diretamente ligadas a várias doenças autoimunes nos seres humanos [14,15].

A utilização de agonistas ou antagonistas das siglecs como alvo terapêutico representa uma nova forma de modular as respostas imunológicas. Além do uso de anticorpos, outras estratégias terapêuticas estão a ser investigadas, baseadas na especificidade de ligação de hidratos de carbono sialilados, designadas de “glycotargeting”. Estas estratégias podem ser utilizadas terapeuticamente para induzir ou inibir a sinalização de siglecs em leucócitos, através de agregação ou bloqueio do local de ligação ao ligando, tendo como alvo terapias de doenças inflamatórias autoimunes e crónicas, bem como do cancro [16]. Por exemplo, ligandos de alta afinidade para CD22 e Siglec-G podem ser usados para induzir tolerância em linfócitos B autorreativos, que poderá ser uma possível estratégia para o tratamento de doenças autoimunes no futuro [17].

\subsection{Glicoimunologia e infeção}

A glicosilação regula a complexa interação que existe entre os patogénios e o hospedeiro, cujos intervenientes-chave são, não só os hidratos de carbono, mas também as lectinas, que já referimos anteriormente.

As lectinas podem ser recetores expressos em células fagocíticas envolvidas no reconhecimento de patogénios, é o caso das lectinas do tipo $\mathrm{C}$ que reconhecem padrões moleculares não-próprios, desempenhando papéis relevantes nos processos de imunidade contra fungos, bactérias e alguns vírus [18,19]. Destacam-se as lectinas transmembranares Dectina 1 e Dectina 2, a DC-SIGN, Mincle, DNGR-1, MMR, DEC205 mas também a colectina solúvel MBL (do inglês manose binding lectin) [20,21]. A Dectina 1 tem um papel importante no reconhecimento de $\beta$-glucanos expressos por fungos. Estudos recentes evidenciaram ainda que a Dectina 1 é capaz de acoplar ao reconhecimento microbiano a ativação de cascatas de sinalização intracelular que regulam várias respostas celulares incluindo fagocitose, autofagia, burst respiratório, produção de numerosas citocinas, incluindo as que polarizam células $\mathrm{T}$ auxiliares para um perfil Th17 [22,23].

A MBL é um recetor que se liga especialmente a resíduos de manose e frutose na superfície de microrganismos e células envelhecidas promovendo a sua fagocitose [24]. Este recetor está ainda envolvido na ativação do sistema do complemento, constituindo assim uma primeira linha de defesa contra patogénios [25].

Os patogénios expressam também lectinas, que neste caso se agrupam em hemaglutininas e adesinas tirando partido dos hidratos de carbono das células do hospedeiro para as invadirem. Como exemplos temos o vírus influenza que se liga via hemaglutinina a uma ligação específica do ácido siálico existente no epitélio bronquiolar [26]. A bactéria Helicobacter pylori, por seu lado, adere via adesinas a hidratos de carbono sialofucosilados do epitélio gástrico $[27,28]$. Curiosamente, os hidratos de carbono microbia- nos reconhecidos por lectinas podem, quando na sua forma livre, bloquear a adesão de bactérias às células humanas, e assim proteger contra infeção por esses microrganismos. Por exemplo, a administração de $\alpha$-manosídeo de metilo reduz a adesão, via adesinas, de Escherichia coli uropatogénicas às mucosas reduzindo significativamente a taxa de infeções do trato urinário [29]. Por outro lado, em determinados microrganismos os hidratos de carbono podem funcionar como escudo, impedindo o seu reconhecimento pelo sistema imunitário. Este é o caso do envelope do vírus da imunodeficiência humana (HIV), em que aproximadamente metade da sua massa é constituída por hidratos de carbono do próprio hospedeiro, ligados por N-glicosilação, evadindo-se do reconhecimento por parte de anticorpos humanos [30].

A glicosilação presente em microrganismos comensais da nossa flora normal (Microbiota) desempenha também um papel importante para o desenvolvimento das relações mutualistas com o hospedeiro e, por conseguinte, a homeostase do sistema imunitário na mucosa do trato gastrointestinal [31]. Os hidratos de carbono de helmintas são capazes de ativar células apresentadoras de antigénios de condicionar o perfil das células $\mathrm{T}$ auxiliares, favorecendo as respostas do tipo Th2, e expandir células $\mathrm{T}$ reguladoras [32].

Em resumo, os hidratos de carbono e as lectinas são peças fundamentais no reconhecimento de patogénios e na infeção, o que os torna alvos promissores para o tratamento de infeções e modulação da resposta imunitária.

\subsection{Glicoimunologia e função dos anticorpos}

As imunoglobulinas ou anticorpos são glicoproteínas, essencialmente $\mathrm{N}$-glicosiladas, nas suas regiões efetoras (Fc), as quais são altamente heterogéneas, sobretudo nos hidratos de carbono terminais. Esta heterogeneidade depende da espécie e do sistema de expressão [33] Estes hidratos de carbono que decoram as Fc influenciam a ligação aos recetores em células efetoras (FcR) ou ao sistema do complemento e têm um papel determinante na função dos anticorpos. Hidratos de carbono com resíduos terminais de ácido siálico, fucose, $N$-acetilglucosamina e manose determinam o tipo de recetor a que se liga o anticorpo e influenciam as reações de citotoxicidade celular dependente de anticorpos enquanto que a galactose terminal afeta a ligação ao complemento (figura 2) [34].

A glicosilação de imunoglobulinas tem relevância nas terapias que utilizam anticorpos. Verificou-se, por exemplo, que a ação dos anticorpos usados no tratamento de doenças inflamatórias autoimunes é absolutamente dependente da presença de hidratos de carbono contendo ácido siálico, pois são estes que permitem a ligação aos recetores celulares e desencadeiam a ação inibitória e anti-inflamatória, ao ligarem a molécula DC-SIGN, específica de células dendríticas $[21,33]$.

\subsection{Glicoimunologia e imunidade tumoral}

A expressão aberrante de hidratos de carbono é uma das assinaturas tumorais. Entre os antigénios glicosilados, expressos aberrantemente, encontram-se hidratos de carbono incompletos, ou seja, cujo elongamento foi prematuramente terminado. É o caso da expressão de uma família de 
hidratos de carbono incompletos ligado por O-glicosilação designados por antigénios Thomsen-Friedenreich (figura 4).

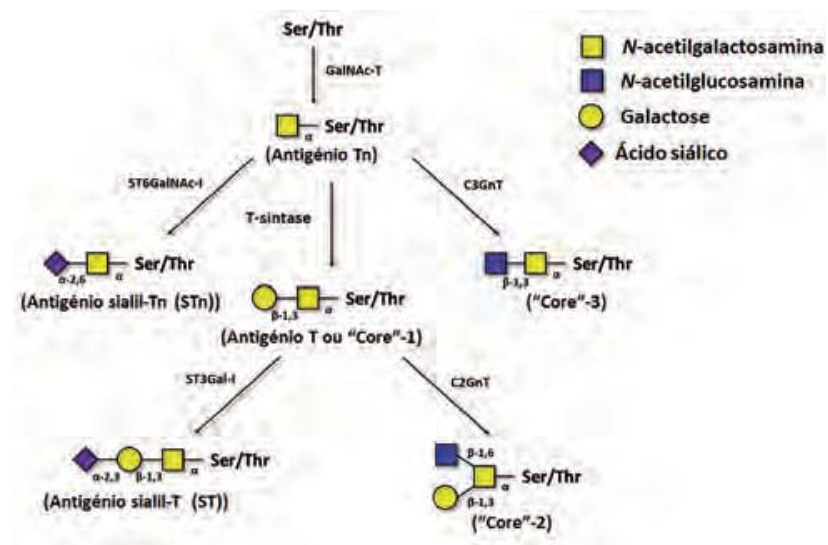

Figura 4 - A família de O-antigénios Thomsen-Friedenreich e sua biossíntese. O antigénio Thomsen-nouveau (Tn) (GalNAc- $\alpha 1-\mathrm{O}-\mathrm{Ser} / \mathrm{Thr}$ ), consiste num resíduo de GalNAc ligado por uma ligação $\alpha$-O- ao grupo hidroxilo dos resíduos de serina ou treonina na cadeia polipeptídica; o antigénio Thomsen-Friedenreich (T) (Galß1-3GalNAc- $\alpha 1-O-S e r / T h r)$, onde um resíduo de galactose (Gal) está ligado a GalNAc; o antigénio sialil Tn (STn), em que o resíduo GalNAc no antigénio Tn está ligado a um ácido siálico no carbono 6; e o sialil-T (ST), em que o resíduo Ga no antigénio T está ligado ao ácido siálico no carbono 3. A sialilação dos antigénios Tn e T bloqueia o alongamento das estruturas. Adaptada de Loureiro et al. Biomolecules 5 (2015) 1783-1809.

A sobre-expressão destes antigénios em tumores humanos deve-se geralmente a defeitos nas vias secretórias dos organelos (retículo endoplasmático e complexo de Golgi) e/ou na expressão alterada de glicosiltransferases [35].

O STn é expresso na maioria dos carcinomas e está ausente nos tecidos saudáveis [36], tendo sido correlacionado com a progressão do cancro, mau prognóstico e também associados a um microambiente imunossupressor [37,38]. Estudos realizados pelo nosso grupo demonstraram que a expressão do antigénio STn em células cancerígenas tem um efeito de supressão da resposta imunológica [38]. Nesse estudo verificou-se que tumores de bexiga com uma expressão elevada de STn apresentam também uma maior presença de células dendríticas (DCs) imaturas e, concomitantemente, níveis diminuídos de citocinas IL-12 e TNF- $\alpha$, indutoras da resposta Th1. In vitro, as DCs cultivadas na presença de células cancerígenas que sobre-expressam STn adquirem um fenótipo mais imaturo, com menor produção de citocinas, e não respondem a estímulos de maturação. Consistente com um perfil tolerogénico, células T cultivadas com DCs pulsadas com antigénios de células cancerígenas expressando STn, não são ativadas e revelam um fenótipo de células reguladoras. In vitro, o bloqueio dos antigénios STn impede o seu efeito tolerogénico, sugerindo que estes antigénios poderão ser alvos terapêuticos para contornar os mecanismos imunossupressores induzidos pelo tumor [38].

Um dos temas de investigação em cancro é a identificação de biomarcadores que permitam detetar precocemente o desenvolvimento de tumores, através de testes relativamente simples como as análises ao sangue. Existem atualmente análises clínicas a marcadores tumorais que são monitorizados principalmente para acompanhar respostas à terapia ou detetar possíveis recidivas. Alguns destes marcadores são hidratos de carbono, como é o caso do sialil Lewis A (CA19-9) em cancro do pâncreas ou do cólon; e do CA15.3, um epítopo da mucina 1, em cancro de mama [39].

\subsection{Glicoimunologia e novas imunoterapias anticancro}

As imunoterapias para tratamento do cancro são estratégias que tiram partido da função imunológica normal do nosso organismo, estimulando-a especificamente contra o tumor. Neste contexto, estão as células dendríticas que são apresentadoras de antigénios profissionais e que têm a capacidade de fazer a ponte entre a imunidade inata e a adquirida. Estas células captam antigénios nos tecidos e iniciam um processo de maturação e migração para os gânglios linfáticos para apresentar os antigénios às células efetoras, os linfócitos. Por sua vez, os linfócitos $\mathrm{T}$ auxiliares induzem os linfócitos B a produzir anticorpos específicos e os linfócitos T citotóxicos destroem as células malignas.

Tirando partido da presença de monócitos no sangue, que são precursores das DCs, é possível produzir em laboratório, a partir destas células, DCs em quantidade suficiente para terapia celular. As DCs são carregadas com antigénios tumorais e ao serem reintroduzidas no organismo do doente vão ativar e instruir os linfócitos no sentido de combaterem os tumores. Apesar de ser uma terapia aprovada em alguns cancros, existe ainda necessidade de compreender os mecanismos moleculares que levam a uma maturação eficiente das DCs e também controlar os estímulos imunossupressores normalmente encontrados no microambiente tumoral e que impedem a resposta imunitária. Com esse objetivo, a investigação do nosso grupo visa contribuir para o melhoramento de imunoterapias. Verificámos que as DCs possuem um conteúdo elevado de ácidos siálicos [42] e que a sua remoção modula a sua potência imunológica e o seu potencial terapêutico $[43,44]$. Assim, a produção de imunoterapias tendo como alvo as estruturas glicosídicas faz todo o sentido e surge com a necessidade de modular as respostas imunitárias, tornando-as mais eficazes. Por outro lado, o uso de anticorpos para bloquear hidratos de carbono imunossupressores, específicos de tumores, como o STn, poderá complementar o resultado terapêutico e melhorar a resposta do sistema imunitário contra tumores [45].

Com estas estratégias, usadas separadamente ou combinadas com outras, esperamos contribuir para o desenvolvimento de terapias mais eficazes e específicas no combate ao cancro.

\section{Doenças congénitas da glicosilação}

Foram identificados, até ao momento, 85 tipos diferentes de doenças congénitas da glicosilação. Estas doenças apresentam um fenótipo muito variável, podendo afetar muitos órgãos ou apenas um e podendo apresentar diferentes graus de severidade. Sabe-se que quase $10 \%$ delas apresentam alterações no sistema imunitário. No entanto, existe disfunção imunitária significativa apenas num pequeno grupo de CDGs [40]. As disfunções imunitárias mais comuns associadas a CDGs são infeções recorrentes, que afetam principalmente alguns doentes com ALG12-CDG (deficientes numa manosiltransferase envolvida na via de N-glicosilação) tendo, em alguns casos levado à morte por pneumonia ou septicemia. 
Na CDG mais comum, que é a PMM2-CDG (CDGIa) (deficiência na enzima que converte manose-6-fosfato em manose-1-fosfato), existe um envolvimento menor do sistema imunitário. Contudo, algumas crianças sofrem de infeções recorrentes e severas (por vezes letais) devidas a níveis baixos de imunoglobulinas (hipogamaglobulinemia). Quando vacinados, os doentes podem não desenvolver imunidade ou perdê-la rapidamente. Para além disso, a migração dos neutrófilos pode estar reduzida, mas a causa subjacente permanece desconhecida. Outros estudos encontraram níveis de citocinas elevados, desencadeando uma resposta inflamatória. Estes níveis anormais de citocinas podem originar complicações como convulsões, observadas em metade dos pacientes PMM2-CDG.

A maioria das infeções em CDG estão associadas a uma diminuição significativa dos níveis de IgG no soro e uma disfunção dos linfócitos $\mathrm{B}$, que poderá ser devida a uma $\mathrm{N}$-glicosilação deficiente das imunoglobulinas, que afeta as suas funções efetoras de ligação ao complemento ou a recetores celulares [41]. No entanto, visto serem doenças raras, existe ainda muito por estudar sobre as possíveis alterações do sistema imunitário nestes doentes. Parece evidente que, devido à ubiquidade dos hidratos de carbono, se possam vir a descobrir mais relações entre os defeitos da glicosilação e disfunções do seu sistema imunitário.

\section{Conclusão geral}

Embora relativamente recente e durante muito tempo negligenciada, a Glicobiologia, e em particular a Glicoimunologia, têm revelado papéis importantes dos hidratos de carbono em diversas funções celulares. Tendo em conta que a ação do sistema imunitário depende primeiramente do reconhecimento celular e molecular, todos os processos são em algum ponto dependentes de hidratos de carbono. Estes intervêm, por exemplo, nos mecanismos de controlo da infeção, facilitando ou impedindo o reconhecimento de organismos patogénicos e controlando o recrutamento de leucócitos para os tecidos infetados; na autoimunidade, facilitando a distinção entre próprio e não próprio (estranho); no controlo da função efetora dos anticorpos; no cancro, sendo por vezes hidratos de carbono exclusivos de células cancerígenas e usados como biomarcadores para a sua deteção mas também na modulação da atividade do sistema imunitário no ambiente tumoral. Assim, os hidratos de carbono surgem como potenciais novos alvos terapêuticos, e o reconhecimento da sua importância permitirá melhorar a eficácia das imunoterapias modernas.

\section{Agradecimentos}

Agradecemos à Carlota Pascoal pelo seu contributo na elaboração das figuras. Z. Silva agradece o financiamento da FCT (SFRH/BPD/108686/2015). Agradecemos também a todos os elementos do grupo de Glicoimunologia, pelo contributo com os resultados da sua investigação e/ou pela leitura e sugestões dadas para a elaboração deste artigo.

\section{Glossário}

Glicoconjugados - são moléculas compostas por proteínas, lípidos ou outros compostos orgânicos ligados a hidratos de carbono.
Glicosamina - termo genérico para designar glucosamina ou galactosamina, por exemplo.

Lectinas - proteínas que se ligam especificamente a determinado tipo de hidratos de carbono. A ligação dos hidratos de carbono a estas proteínas é o principal modo de reconhecimento e descodificação da informação contida nas estruturas glicosiladas e sua tradução numa ação biológica. Colectinas — proteínas solúveis do sistema imunitário inato e que desempenham um papel importante na defesa contra bactérias, vírus e fungos. Caracterizam-se por serem constituídas por um domínio semelhante ao colagénio e por domínios de reconhecimento de hidratos de carbono (CRDs). A ligação aos hidratos de carbono é dependente de cálcio e da trimerização dos CRDs.

\section{Abreviaturas}

ADCC - citotoxidade celular dependente de anticorpos, do inglês antibody-dependent cell-mediated cytotoxicity CDG - doenças congénitas da glicosilação, do inglês congenital disorders of glycosylation

CRDs - domínios de reconhecimento de hidratos de carbono, do inglês carbohydrate recognition domains

DCs - células dendríticas, do inglês dendritic cells

Fc - Região efetora de um anticorpo. A porção do anticorpo responsável pela ligação a recetores celulares ou a moléculas do complemento e que vai desencadear a resposta imunitária

Ig - Imunoglobulina ou anticorpo

MHC - complexo major de histocompatibilidade, do inglês major histocompatibiliy complex

NK - células natural killer

\section{Referências}

[1] H. Ghazarian, B. Idoni, S.B. Oppenheimer, Acta Histochem. 113 (2011) 236-247.

[2] J.J. García-Vallejo, Y. van Kooyk, Immunol. Rev. 230 (2009) 22-37.

[3] H.S. Goodridge, A.J. Wolf, D.M. Underhill, Immunol. Rev. 230 (2009) 38-50.

[4] S. Iborra, D. Sancho, Immunobiology 220 (2015) 175-184.

[5] A. Etzioni, Adv. Exp. Med. Biol. 601 (2007) 51-60.

[6] S. Hanna, A. Etzioni, Ann. N. Y. Acad. Sci. 1250 (2012) 50-55.

[7] R.C. Preston, R.P. Jakob, F.P.C. Binder, C.P. Sager, B. Ernst, T. Maier, J. Mol. Cell Biol. 8 (2016) 62-72.

[8] J.C. Pickup, M.B. Mattock, M.A. Crook, G.D. Chusney, D. Burt, A.P. Fitzgerald, Diabetes Care 18 (1995) 1100-1103.

[9] S.S. Pinho, C.A. Reis, Nat. Rev. Cancer 15 (2015) 540-555 .

[10] M.B. Jones, D.M. Oswald, S. Joshi, S.W. Whiteheart, R. Orlando, B.A. Cobb, Proc. Natl. Acad. Sci. 113 (2016) 7207-7212.

[11] J.F. Seite, D. Cornec, Y. Renaudineau, P. Youinou, R.A. Mageed, S. Hillion, Blood 116 (2010) 1698-1704

[12] J. Müller, L. Nitschke, Nat. Rev. Rheumatol. 10 (2014) 422-428.

[13] L. Nitschke, Glycobiology 24 (2014) 807-817

[14] I. Surolia, S.P. Pirnie, V. Chellappa, K.N. Taylor, A. Cariappa, J. Moya, H. Liu, D.W. Bell, D.R. Driscoll, S. Diederichs, K. Haider, I. Netravali, S. Le, R. Elia, E. Dow, A. Lee, J. Freudenberg, P.L. De Jager, Y. Chretien, A. Varki, 
M.E. MacDonald, T. Gillis, T.W. Behrens, D. Bloch, D. Collier, J. Kornezigk, D.K. Podolsky, D. Hafler, M. Murali, B. Sands, J.H. Stone, P.K. Gregersen, S. Pillai, Nature 466 (2010) 243-247.

[15] V.S. Mahajan, S. Pillai, Immunol. Rev. 269 (2016) 145-161.

[16] C. Jandus, H.-U. Simon, S. von Gunten, Biochem. Pharmacol. 82 (2011) 323-332.

[17] M.S. Macauley, P.R. Crocker, J.C. Paulson. Nat. Rev. Immunol. 14 (2014) 653-666.

[18] S.E. Hardison, G.D. Brown, Nat. Immunol. 13 (2012) 817$-822$.

[19] J.P. Upham, D. Pickett, T. Irimura, E.M. Anders, P.C. Reading, J. Virol. 84 (2010) 3730-3737.

[20] I.M. Dambuza, G.D. Brown, Curr. Opin. Immunol. 32 (2015) 21-27.

[21] E. van Liempt, C.M.C. Bank, P. Mehta, J.J. García-Vallejo, Z.S. Kawar, R. Geyer, A. Alvarez, R. D. Cummings, Y. van Kooyk, I. van Die, FEBS Lett. 580 (2006) 6123-6131.

[22] J. Ma, C. Becker, C. Reyes, D.M. Underhill, J. Immunol. 192 (2014) 1356-1360.

[23] S.E. Hardison, G.D. Brown, Nat. Immunol. 13 (2012) 817-822 .

[24] W.K.E. Ip, K. Takahashi, R.A. Ezekowitz, L.M. Stuart, Immunol. Rev. 230 (2009) 9-21.

[25] P. Garred, N. Genster, K. Pilely, R. Bayarri-Olmos, A. Rosbjerg, Y.J. Ma, M.O. Skjoedt, Immunol. Rev. 274 (2016) 74-97.

[26] L. Byrd-Leotis, R.D. Cummings, D.A. Steinhauer, Int. J. Mol. Sci. 18 (2017) 1541.

[27] S.S. Pinho, S. Carvalho, R. Marcos-Pinto, A. Magalhães, C. Oliveira, J. Gu, M. Dinis-Ribeiro, F. Carneiro, R. Seruca, C.A. Reis, Trends Mol. Med. 19 (2013) 664-676.

[28] N.T. Marcos, A. Magalhães, B. Ferreira, M.J. Oliveira, A.S. Carvalho, N. Mendes, T. Gilmartin, S. R. Head, C. Figueiredo, L. David, F. Santos-Silva, C. A. Reis, J. Clin. Invest. 118 (2008) 2325-2336.

[29] C.N. Spaulding, R.D. Klein, S. Ruer, A.L. Kau, H.L. Schreiber, Z.T. Cusumano, K.W. Dodson, J.S. Pinkner, D.H. Fremont, J.W. Janetka, H. Remaut, J.I. Gordon, S.J. Hulgren, Nature 546 (2017) 528-532.

[30] K.J. Doores, FEBS J. 282 (2015) 4679-4691.
[31] L.E. Comstock, Cell Host Microbe 5 (2009) 522-526.

[32] S. Tundup, L. Srivastava, D.A. Harn Jr. Ann. N. Y. Acad. Sci. 1253 (2012) E1-E13.

[33] R.M. Anthony, F. Wermeling, J.V. Ravetch. Ann. N. Y. Acad. Sci. 1253 (2012) 170-180.

[34] J. Jez, B. Antes, A. Castilho, M. Kainer, S. Wiederkum, J. Grass, F. Rüker, M. Woisetschläger, H. Steinenkellner, J. Biol. Chem. 287 (2012) 24313-24319.

[35] A. Varki, R. Kannagi, B. Toole, P.Stanley, "Essentials of Glycobiology", Cold Spring Harbor (NY) 2015.

[36] P.A. Videira, M. Correia, N. Malagolini, H.J. Crespo, D. Ligeiro, F.M. Calais, H. Trindade, F. Dall'Olio, BMC Cancer 9 (2009) 357.

[37] J.A. Ferreira, P.A. Videira, L. Lima, S. Pereira, M. Silva, M. Carrascal, P.F. Severino, E. Fernandes, A. Almeida, C. Costa, R. Vitorino, T. Amaro, M.J. Oliveira, C.A. Reis, F. Dall'Olio, F. Amado, L.L. Santos. Mol. Oncol. 7 (2013) 719-731.

[38] M.A. Carrascal, P.F. Severino, M.G. Cabral, M. Silva, J.A. Ferreira, F. Calais, H. Quinto, C. Pen, D. Ligeiro, L.L. Santos, F. Dall'Olio, P.A. Videira, Mol. Oncol. 8 (2014) 753-765.

[39] J.C. Chang, M. Kundranda, Int. J. Mol. Sci. 18 (2017) 667.

[40] M. Monticelli, T. Ferro, J. Jaeken, V.R. Ferreira, P.A. Videira, J. Inherit. Metab. Dis. 39 (2016) 765-780.

[41] R.M. Anthony, J. V. Ravetch, J. Clin. Immunol. 30 (2010) 9-14.

[42] P.A Videira, I.F. Amado, H.J. Crespo, M.C. Algueró, F. Dall'Olio, M.G. Cabral, H. Trindade, Glycoconj. J. 25 (2008) 259-268.

[43] M. Silva, Z. Silva, G. Marques, T. Ferro, M. Gonçalves, M. Monteiro, S.J. van Vliet, E. Mohr, A.C. Lino, A.R. Fernandes, F.A. Lima, Y. van Kooyk, T. Matos, C.E. Tadokoro, P.A. Videira, Oncotarget. 7 (2016) 41053-41066.

[44] H.J. Crespo, M.G. Cabral, A.V. Teixeira, J.T.Y. Lau, H. Trindade, P.A. Videira, Immunology 128 (2009) e621e631.

[45] L.R. Loureiro, M.A. Carrascal, A. Barbas, J.S. Ramalho, C. Novo, P. Delannoy, P.A. Videira. Biomolecules 5 (2015) 1783-1809.

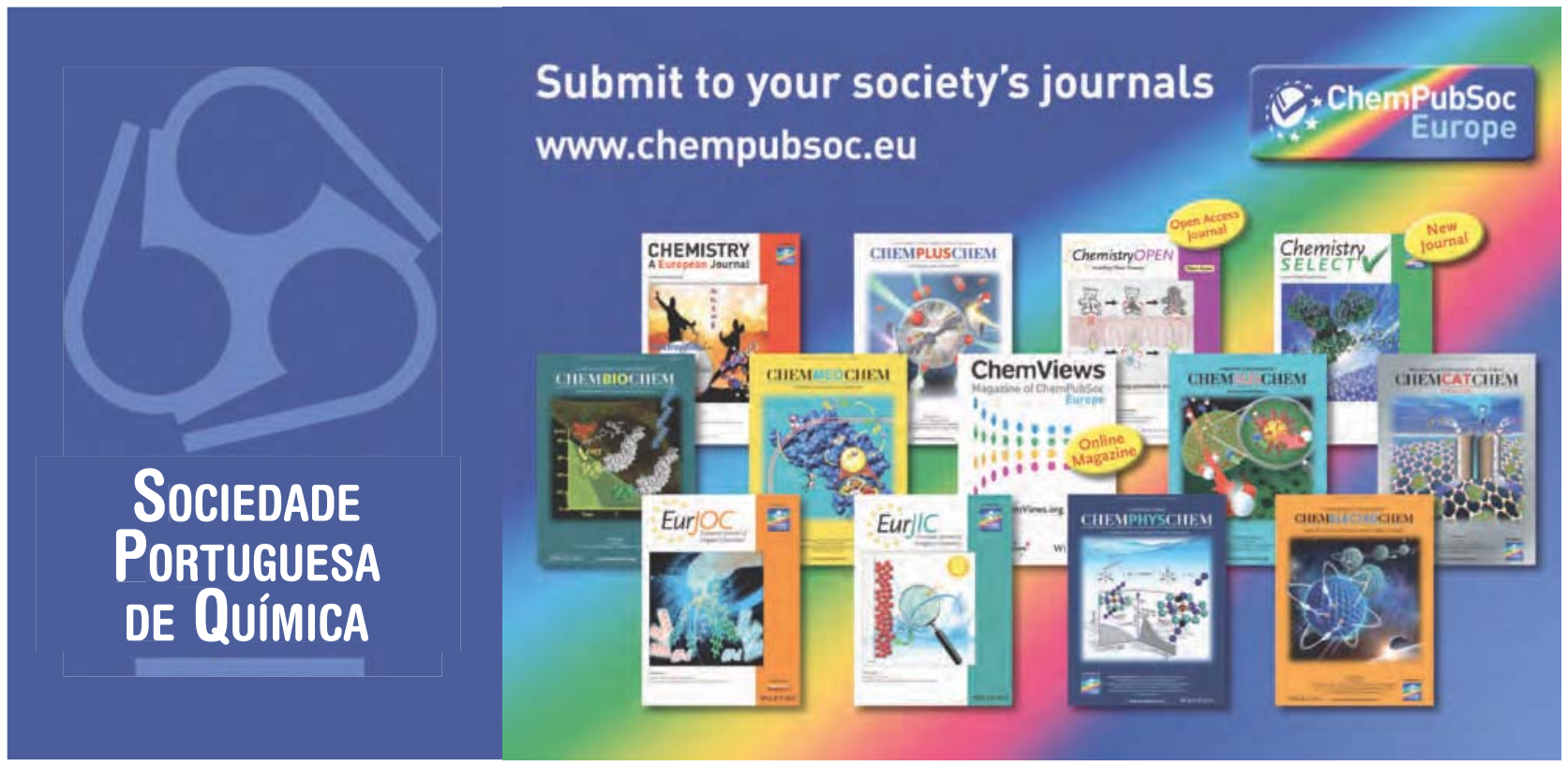

